\title{
Ligaments vs tendons in joint reconstruction: a review of histology and biomechanics
}

\author{
Susan M. Ge ${ }^{1}$ \\ Nayif Alnaif ${ }^{2}$ \\ Alain J. Azzi ${ }^{2}$ \\ Teanoosh Zadeh ${ }^{2}$ \\ 1 Division of Orthopaedic Surgery, McGill University \\ Health Centre, Montreal, Canada \\ 2 Division of Plastic and Reconstructive Surgery, \\ McGill University Health Centre, Montreal, Canada
}

Corresponding author:

Alain Joe Azzi

Division of Plastic and Reconstructive Surgery

McGill University Health Center

1650 Cedar Ave

H3G 1 A4 Montreal, QC

E-mail: alain.azzi@mail.mcgill.ca

\section{Summary}

Introduction: In the current literature, there is no consensus of using tendons vs ligaments as a graft source for joint reconstruction. The aim of this review is to determine the potential superiority of tendons vs ligaments in joint reconstruction. Methods: A literature search was performed to find relevant articles exploring the properties of tendons and ligaments. Functional, structural (gross and histological), biochemical, and biomechanical properties were compared.

Results: Tendons have a stiffer structure to hold muscle to bone whereas ligaments have a more elastic structure to allow for movement between bones. Ligaments have a narrower crimp distance, ovoid cells, and a higher concentration of alpha smooth muscle associated with higher elasticity and tolerated strain. It has been shown that tendons undergo "ligamentization" when used to reconstruct ligaments. However, even after remodelling, important differences still persist, never reaching the functional status of the intact ligament.

Conclusions: There is a theoretical clinical advantage of using ligaments as a graft source in complex multiaxial joints where stretching and full range of motion (ROM) is crucial (e.g. radiocarpal, carpal joints). Tendon grafts may be more desir- able in lower limb reconstructions and in mainly uniaxial joints where excessive and constant vector of stress is applied.

Level of evidence: Illa.

KEY WORDS: tendons, ligaments, ligament reconstruction, joints, histology, biomechanics.

\section{Introduction}

Traumatic or degenerative ligamentous injuries often require joint reconstruction with a tendon or ligament autograft. This includes a wide array of pathologies ranging from $A C L$ tears in the knee to scapholunate instability in the wrist. Tendon autografts are currently the most commonly used method for articular ligament reconstruction, either from the upper or lower extremities ${ }^{1}$. Main complications include decreased range of motion (ROM) and graft stretching. Bone-ligament-bone autografts is another alternative for reconstructing ligaments ${ }^{2}$. These grafts have been successful with the main complications being graft stretching and pull out. The use of either tendons or ligaments in ligament reconstruction of musculoskeletal injuries show favourable results in terms of functionality and patient satisfaction, although there still exists many challenges to overcome ${ }^{2,3}$.

The literature comparing the clinical outcomes of these two techniques is complicated and often difficult to interpret. Tendons and ligaments are often not differentiated and at times these terms are used interchangeably. In carpal ligament reconstruction, the structural and functional differences between tendons and ligaments are also unclear. Interesting observations have been made in tissue engineering research regarding the differences in behaviour, in terms of contractile activity, in ligament and tendon cells grown in vitro ${ }^{4}$. This has sparked a question about the role of myofibroblasts in ligaments vs tendons and whether the properties of tendons and ligaments contribute to different clinical outcomes in vivo. There have been few if any clinical studies directly comparing long-term outcomes of ligament reconstruction using tendons vs ligaments. Despite this lack of comparable studies, there have been a number of histological, biochemical and biomechanical studies comparing various tendon and ligament properties and how these correlate with function ${ }^{5}$. The aim of this study is to review the literature to determine if there is a theoretical clinical advantage of using either ten- 
dons or ligaments as a graft source to reconstruct joint ligaments.

\section{Methods}

An Ovid MEDLINE database search was conducted using the variations of the following terms: "ligament, tendon, reconstruction, biochemical, biomechanics, histology, morphology, structure, myofibrils, alpha smooth muscle actin (Tab. I, for a full list of the search terms). Relevant references from included articles were also reviewed. Inclusion criteria included all articles that explored the properties of tendons and ligaments from 1977 to 2015 in both human and animal models. Although both animal and human models were considered, emphasis was placed more on human models except in biochemical studies where more work was done in animal models. Exclusion criteria were articles comparing autografts with allografts, the addition of any growth factors and/or scaffolds, studies in skeletally immature models as well as articles not in the English language (Fig. 1). Studies were reviewed by two independent reviewers, using the same exclusion/inclusion criteria.
Once relevant articles were found, we encountered several issues. 1) Many of the biomechanical studies used different methods; therefore, the relative differences between tendons and ligaments were explored instead of comparing absolute numbers between studies. 2) In a number of articles, the patellar ligament was considered to be a tendon while in others it was considered to be a ligament, altering some of the results. In either case, the patellar ligament is a structure attached to two bones, yet contiguous with the quadriceps tendon and muscle. This likely alters its properties so in the studies that used the patellar ligament/tendon along with other ligaments and tendons, the data for the patellar ligament/tendon was excluded when possible and interpreted with caution. This study meets the ethical standards of the journal ${ }^{6}$. The current review followed the guidelines provided by the Preferred Reporting Items for Systematic Reviews and Meta-Analyses (PRISMA) statement ${ }^{7}$.

\section{Results and discussion}

A total of 19 studies fit the inclusion criteria (Tab. II). Many articles discuss separately the different proper-

Table I. Search Strategy (Ovid MEDLINE).

\begin{tabular}{|c|c|c|}
\hline$\#$ & Search Statement & Results \\
\hline 1 & Tendons/ & 24305 \\
\hline 2 & Ligaments/ & 8141 \\
\hline 3 & 1 or 2 & 31705 \\
\hline 4 & 1 and 2 & 741 \\
\hline 5 & Biomechanic $^{\star} . \mathrm{mp}$. & 129295 \\
\hline 6 & Biochemic*.mp. & 351722 \\
\hline 7 & Histology/ & 4228 \\
\hline 8 & Morpholog*.mp. & 537892 \\
\hline 9 & Structur*.mp. & 2187963 \\
\hline 10 & 5 or 6 or 7 or 8 or 9 & 3010583 \\
\hline 11 & Myofibrils/ & 9533 \\
\hline 12 & Alpha smooth muscle actin.mp. & 10906 \\
\hline 13 & Actins/ & 52538 \\
\hline 14 & 12 or 13 or 14 & 68020 \\
\hline 15 & Reconstructive Surgical Procedures/ or reconstruct ${ }^{\star} . \mathrm{mp}$. & 269916 \\
\hline 16 & 3 and 14 & 177 \\
\hline 17 & 4 and 10 & 314 \\
\hline 18 & 3 and 10 and 15 & 1473 \\
\hline 19 & 16 or 17 or 18 & 1926 \\
\hline 20 & Limit 19 to (yr="1977 - 2015" and english) & 1562 \\
\hline
\end{tabular}




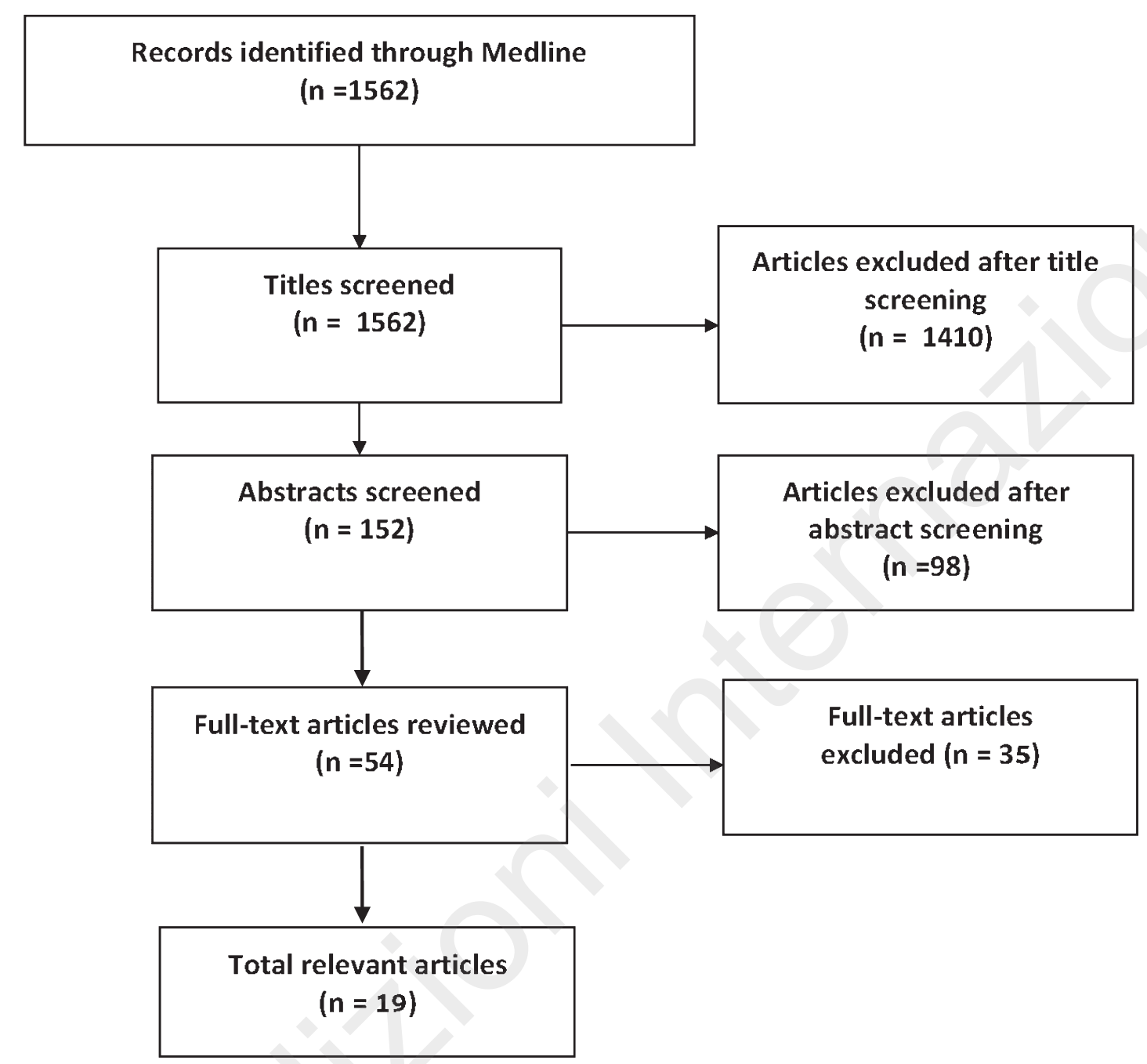

Figure 1. Flow Diagram.

ties of tendons and ligaments. These properties are usually divided into functional, structural (gross and histological), biochemical, and biomechanical. These properties however are intertwined and in order to present a more comprehensive picture must be discussed together.

\section{Cell maturity and collagen properties}

Tendons and ligaments are generally indistinguishable with the naked eye but have significant histological and biochemical differences. Tendons are more hypocellular and contain thinner spindle-shaped cells compared to ligaments. As such, tendons have a lower DNA content ${ }^{5}$. In lower limbs of rabbits, both tendons and ligaments are composed mainly of type I collagen ${ }^{5,8,9}$. Whereas tendons contain more total collagen, they contain $<5 \%$ of type III collagen while ligaments contain up to $12 \%{ }^{5}$. In a study of human carpal ligaments, type III collagen was found to make up $19 \%$ of the total collagen in extrinsic carpal liga- ments and $41 \%$ of intrinsic carpal ligaments ${ }^{10}$. As we know from wound healing, initially in the proliferative phase, fibroblasts produce abundant amounts of type III collagen. As the fibroblasts mature, they take on a spindle shaped morphology and produce type I collagen that replaces much of the initial type III collagen. Therefore, type III collagen produces a more immature collagen with higher elasticity compared to its stronger more mature counterpart. In a later human study however, Fujii et al. found no significant amounts of type III collagen on biochemical analysis in lower limb ligaments but does note that the ACL contained more elastic, immature looking collagen fibres $^{9}$. Collagen crosslinking is also an important determinant of the material properties of a tissue. In two different studies, ligaments were found to have a higher ratio of dihydroxylysinonorleucine (DHLNL) plus hydroxylysinonorleucine (HLNL) cross-links compared to hydroxymeodesmosine (HHMD), and more DHLNL cross-links compared to HLNL cross-links ${ }^{5,9}$. 
Table II. List of included studies.

\begin{tabular}{|c|c|c|c|c|c|c|}
\hline Author & Year & Subject & $\mathbf{N}$ & Structure examined & Follow-up & Conclusion \\
\hline Ippolito et al. ${ }^{15}$ & 1977 & Rabbit & N/A & Achilles tendon & $\mathrm{N} / \mathrm{A}$ & $\begin{array}{l}\text { Actin filaments within tenocyte } \\
\text { cytoplasm suggest that tendons have } \\
\text { contractile activity }\end{array}$ \\
\hline Amiel et al. ${ }^{5}$ & 1984 & Rabbit & 6 & $\begin{array}{l}\text { ACL, PCL, MCL, } \\
\text { Patellar } \\
\text { tendon/ligament, } \\
\text { Achilles tendon }\end{array}$ & $\mathrm{N} / \mathrm{A}$ & $\begin{array}{l}\text { Despite gross similarities between } \\
\text { tendons and ligaments, they have } \\
\text { unique histological and biochemical } \\
\text { characteristics }\end{array}$ \\
\hline Frank et al. ${ }^{8}$ & 1985 & Multiple & $\mathrm{N} / \mathrm{A}$ & $\begin{array}{l}\text { Histologic, biochemical, } \\
\text { and mechanical } \\
\text { properties of ligaments }\end{array}$ & $\mathrm{N} / \mathrm{A}$ & $\begin{array}{l}\text { Ligaments are highly sophisticated } \\
\text { structures with highly specific functions; } \\
\text { replacing them with another structure } \\
\text { whether biological or artificial is a } \\
\text { difficult task }\end{array}$ \\
\hline Butler et al. ${ }^{20}$ & 1986 & Human & 3 & $\begin{array}{l}\mathrm{ACL}, \mathrm{PCL}, \mathrm{LCL}, \text { Patellar } \\
\text { tendon }\end{array}$ & $\mathrm{N} / \mathrm{A}$ & $\begin{array}{l}\text { Maximum stress and linear modulus } \\
\text { higher for patellar tendon. Otherwise, no } \\
\text { significant biomechanical differences } \\
\text { between maximum strain in the tissues } \\
\text { examined }\end{array}$ \\
\hline Kuhlmann et al. ${ }^{13}$ & 1990 & Human & 10 & $\begin{array}{l}\text { Wrist ligaments, } \\
\text { tendons and palmar } \\
\text { aponeurosis }\end{array}$ & $\mathrm{N} / \mathrm{A}$ & $\begin{array}{l}\text { Tendons are strong but show little } \\
\text { elasticity whereas ligaments are more } \\
\text { elastic but weaker }\end{array}$ \\
\hline Fuji et al. ${ }^{9}$ & 1994 & Human & 5 & $\begin{array}{l}\mathrm{ACL}, \mathrm{PCL}, \mathrm{MCL}, \mathrm{LCL} \\
\text { Patellar tendon, Gracilis } \\
\text { tendon, lliotibilal band }\end{array}$ & $\mathrm{N} / \mathrm{A}$ & $\begin{array}{l}\text { Ligaments and tendons showed } \\
\text { different types of collagen crosslinks; } \\
\text { ligaments also contain more immature } \\
\text { collagen }\end{array}$ \\
\hline Johnston et al. ${ }^{10}$ & 1995 & Human & 20 & $\begin{array}{l}\text { Radiolunate, } \\
\text { radioscaphocapitate, } \\
\text { scapholunate, } \\
\text { lunotriquetral ligaments }\end{array}$ & $\mathrm{N} / \mathrm{A}$ & $\begin{array}{l}\text { More type III collagen in intrinsic } \\
\text { ligaments of the wrist; extrinsic } \\
\text { ligaments stiffer; intrinsic ligaments } \\
\text { better adapted structurally for more } \\
\text { elongation before permanent } \\
\text { deformation }\end{array}$ \\
\hline $\begin{array}{l}\text { Schechtman and } \\
\text { Bader }{ }^{24}\end{array}$ & 1997 & Human & 90 & $\begin{array}{l}\text { Extensor digitorum } \\
\text { longus }\end{array}$ & $\mathrm{N} / \mathrm{A}$ & $\begin{array}{l}\text { Tendons fatigue in a predictable linear } \\
\text { manner explaining the commonness of } \\
\text { overuse injuries }\end{array}$ \\
\hline $\begin{array}{l}\text { Benjamin and } \\
\text { Ralphs }{ }^{12}\end{array}$ & 1997 & Multiple & N/A & $\begin{array}{l}\text { Histology and } \\
\text { histopathology of } \\
\text { tendons and ligaments }\end{array}$ & N/A & $\begin{array}{l}\text { Overview of tendon and ligament } \\
\text { properties: structure, biochemical, blood } \\
\text { and nerve supply, specialized regions, } \\
\text { growth and development, exercise and } \\
\text { stress deprivation }\end{array}$ \\
\hline $\begin{array}{l}\text { Murray and } \\
\text { Spector }{ }^{16}\end{array}$ & 1999 & Human & 24 & $\mathrm{ACL}$ & $\mathrm{N} / \mathrm{A}$ & $\begin{array}{l}\text { Three histologically different zones in } \\
\text { the anteromedial bundle of the ACL; } \\
\text { distal spheroid zone had a lower density } \\
\text { of cells, few blood vessels and shorter } \\
\text { crimp length compared to proximal } \\
\text { ovoid and fusiform zones. All cells } \\
\text { stained for alpha smooth muscle actin } \\
\text { but was more concentrated in cells } \\
\text { located at areas of crimp }\end{array}$ \\
\hline $\begin{array}{l}\text { Benjamin and } \\
\text { Ralphs }^{14}\end{array}$ & 2000 & Multiple & $\mathrm{N} / \mathrm{A}$ & $\begin{array}{l}\text { Biochemical } \\
\text { histopathologic } \\
\text { properties of tendons } \\
\text { and ligaments }\end{array}$ & $\mathrm{N} / \mathrm{A}$ & $\begin{array}{l}\text { Tendon cells linked mechanically by } \\
\text { longitudinal actin stress fibres } \\
\text { associated with adherence junctions; } \\
\text { contractile actin filaments found in } \\
\text { myofibroblasts associated with ligament } \\
\text { healing and remodelling }\end{array}$ \\
\hline Spector ${ }^{17}$ & 2001 & Multiple & $\mathrm{N} / \mathrm{A}$ & $\begin{array}{l}\text { Biochemical } \\
\text { histopathologic } \\
\text { properties of tendons } \\
\text { and ligaments }\end{array}$ & $\mathrm{N} / \mathrm{A}$ & $\begin{array}{l}\text { Smooth muscle actin is found in both } \\
\text { normal and healing tendons and } \\
\text { ligaments but ratios of polymerized vs } \\
\text { non-polymerized forms vary in different } \\
\text { tissues; contractile behaviour contribute } \\
\text { to: ECM modelling, production of in situ } \\
\text { strain (in ligaments), contraction of } \\
\text { wounds, retraction of ruptured tissues }\end{array}$ \\
\hline
\end{tabular}


Continue from Table II.

\begin{tabular}{lllll}
\hline Spector $^{4}$ & 2002 & Multiple & N/A & $\begin{array}{l}\text { Contractile behaviour of N/A } \\
\text { tendons and ligaments }\end{array}$
\end{tabular}

Contractile alpha smooth muscle actin expressed in vivo in articular chondrocytes, meniscal cells, ligament cells, intervertebral disc cells, osteoblasts

\begin{tabular}{lllll}
\hline Weiler et al. ${ }^{18}$ & 2002 & Ovine & 36 & $\begin{array}{l}\text { ACL replaced with } \\
\text { achilles tendon graft }\end{array}$
\end{tabular}

$6,9,12,24$, ACL cells ovoid whereas achilles 52,104 tendon cells fusiform, higher total weeks myofibroblasts and shorter crimp length in ACL compared to achilles tendon; with early remodelling and "ligamentization" both cell shape, myofibroblast number and crimp length of graft approached that of ligament however ligament substitute has not reached functional status of intact $A C L$

\begin{tabular}{lllll}
\hline Rumian et al. ${ }^{11} \quad 2007$ & Ovine 3 & ACL, PCL, MCL, LCL, N/A \\
& & extensor digitorum \\
& longus, extensor \\
& \\
& & digitorum superficialis, \\
& patellar tendon
\end{tabular}
Ligaments had more small sized fibrils whereas tendons have more medium to large sized fibrils. Tendons also have lower water content and higher collagen content; tendons are functionally adapted to cope with larger loads than ligaments, but ligaments are able to stretch further under load

\begin{tabular}{|c|c|c|c|c|c|c|}
\hline Jung et al. ${ }^{21}$ & 2009 & Multiple & N/A & $\begin{array}{l}\text { Biomechanical } \\
\text { properties of tendons } \\
\text { and ligaments }\end{array}$ & $\mathrm{N} / \mathrm{A}$ & $\begin{array}{l}\text { Modulus of elasticity and ultimate } \\
\text { tensile strength generally higher in } \\
\text { tendons while ultimate strain generally } \\
\text { higher in ligaments }\end{array}$ \\
\hline Claes et al. ${ }^{22}$ & 2011 & Human & $\mathrm{N} / \mathrm{A}$ & $\mathrm{ACL}$ & $\mathrm{N} / \mathrm{A}$ & $\begin{array}{l}\text { Tendon grafts replacing the ACL over } \\
\text { time undergo a "ligamentization" } \\
\text { process that make the tendons } \\
\text { resemble ligaments. Although graft } \\
\text { remodelling seem to make tendon grafts } \\
\text { appear ligamentous under light } \\
\text { microscopy on an ultrastructural levels } \\
\text { differences persist such as a more } \\
\text { unimodal collagen fibril diameter } \\
\text { distribution }\end{array}$ \\
\hline Weiss et al. ${ }^{19}$ & 2012 & Human & 2 & $\begin{array}{l}\text { ACL, semitendinosis, } \\
\text { gracilis, quadriceps, } \\
\text { tibialis anterior tendons }\end{array}$ & $\mathrm{N} / \mathrm{A}$ & $\begin{array}{l}\text { Correlation found between } \\
\text { myofibroblast density and crimp } \\
\text { frequency, ovoid; spheroid } \\
\text { myofibroblasts show shorter crimp } \\
\text { distance than fusiform myofibroblasts }\end{array}$ \\
\hline Proffem et al. ${ }^{23}$ & 2013 & Porcine & 48 & $\begin{array}{l}\text { ACL replaced with } \\
\text { bone-patellar tendon- } \\
\text { bone graft }\end{array}$ & $\begin{array}{l}6,12 \\
\text { months }\end{array}$ & $\begin{array}{l}\text { Early ligament function dependent on } \\
\text { cellular population whereas early graft } \\
\text { function dependent on maintenance of } \\
\text { organized collagen; after } 12 \text { months, } \\
\text { ligament repair dependent more on } \\
\text { collagen organization while graft } \\
\text { correlated with total cellular number }\end{array}$ \\
\hline
\end{tabular}

N/A, not available; ACL, anterior cruciate ligament; PCL, posterior cruciate ligament; $\mathrm{MCL}$, medial collateral ligament; $\mathrm{LCL}$ lateral collateral ligament; ECM, extracellular matrix.

Studies have shown that there is a negative correlation between tissue age/maturity and the amount of reducible cross-links ${ }^{9}$. Since DHLNL is the main reducible collagen cross-link, it can be said that ligaments contain a higher amount of reducible crosslinks compared to tendons, and as thus, have a more immature collagen structure.

Another component of tendons and ligaments are glycosaminoglycans (GAGs) contained in the ground substance around the collagen fibres. These molecules are highly attracted to water and are found abundantly in synovial fluid and nucleus pulposus of intervertebral disks due to their function in lubrication and shock absorption. In lower limb studies, ligaments were found to have higher levels of GAGs. Amounts were highest in the smaller cruciate ligaments with lower amounts in the larger collateral ligaments. All ligaments however, contained more GAGs than tendons ${ }^{5}$. Although in another study using ovine tissue, the mass of GAGs per mg of dry weight was not consistent with these earlier results, ligaments were found to contain consistently more water as a 
percent of total weight compared to tendons with a strong correlation $(r=0.73)$ between percent water and GAG content ${ }^{11}$. These water-binding GAGs likely decrease shear stress between ligament fibres and contribute to ligament elasticity. This may be of protective benefit, allowing ligaments to stretch more under tension without rupture 8,11 .

\section{Myofibroblasts and ultrastructural fibre qualities}

Tendons and ligaments are composed of fibroblasts and fibres arranged in an undulating wave pattern referred to as a "crimp pattern" in the literature ${ }^{5,8,12}$. Crimp frequency refers to the number of wave cycles over a given distance, and crimp length is the width of a single wave cycle. In this way, crimp frequency has a negative correlation with crimp length. In a study comparing tendons and ligaments of the wrist in adult human cadavers, ligaments were noted to have increased crimp frequency allowing fibres to elongate without rupture $8,12,13$. This increased crimp frequency has been found to be associated with myofibroblast density and cell type. Myofibroblasts are fibroblasts containing alpha smooth muscle actin (SMA). These SMA containing cells are able to contract and transmit forces to the extracellular matrix. Initially thought to be involved only in healing granulation tissue and wound contraction, these cells are also found in intact tendons and ligaments ${ }^{4,14-18}$. Myofibroblast density was associated with increased crimp frequency with $r=0.67$ in the porcine anterior cruciate ligament and $r=0.43-0.81$ in porcine tendons ${ }^{19}$. There are 3 different types of myofibroblasts with different distribution throughout tendons and ligaments: fusiform, ovoid and spheroid ${ }^{18,19}$. Ligaments contain a large proportion of ovoid and spheroid shaped myofibroblasts whereas in tendons, the predominant cell type was fusiform ${ }^{16,18,19}$. In a human ACL study looking at all cells, and not solely myofibroblasts, there was a higher cell density in fusiform and ovoid cell dominant areas compared to spheroid. The data regarding specifically the SMA containing myofibroblast density demonstrated a higher percentage of SMA containing cells in the spheroid type cells but these results were not statistically significant ${ }^{16}$. In terms of cell type and crimp, fusiform myofibroblasts showed a lower crimp frequency compared with ovoid or spheroid predominant areas ${ }^{19}$. In human studies it was observed that fusiform cells had the highest crimp length followed by ovoid and spheroid cells ${ }^{16}$. Ovine studies showed similar results with ligaments having significantly lower crimp length compared to tendon ${ }^{18}$. From this data it can be summarized that ovoid and spheroid cell types are associated with a higher proportion of SMA containing myofibroblasts and thus, increased crimp frequency and decreased crimp length. Since ligaments contain a higher number of these cells, they are able to stretch further under the same load compared to tendons.

In addition to crimp, there are additional fibre qualities that differ between tendons and ligaments. Due to the physiology of muscle contraction, tendons are structured to resist stress distributed in a linear manner resulting in fibres arranged in parallel. Ligaments on the other hand must resist multi-axial loading, with fibres that are not distributed as uniformly as compared to tendons ${ }^{11}$. This is even more the case in intrinsic carpal ligaments that are required to prevent carpal bone rotation and displacement in all directions ${ }^{10}$. Rumian et al. also found a differential distribution of collagen fibres of various diameters ${ }^{11}$. In ovine ligaments there was a larger amount of small diameter fibrils compared to tendons with intra-articular ligaments having a second peak of medium diameter fibrils. Tendons, like these intra-articular ligaments, also had a bimodal distribution but with medium and large diameter fibrils instead of small and medium. This was similar to what was previously reported by Frank et al. in rabbit models and is likely associated with the higher amounts of type III collagen found in ligaments ${ }^{8}$.

\section{Biomechanical characteristics}

The functional and structural differences between tendons and ligaments are probably most evidently reflected in their biomechanical properties. Tendons transmit mechanical force from muscles in order to move joints. Therefore, they must stretch enough to allow for muscle contraction, yet be stiff enough to store and conduct this force in a linear manner. Ligaments however hold bones together and must be elastic enough to allow movement and stretching in all directions while at the same time provides stable support to the bones being held together ${ }^{11-13}$. Biomechanical studies show that when stress and strain are plotted for human tendons and ligaments, the relationship increases concavely before plateauing and a rapid decline to failure $8,13,20$. In these graphs, the slope of the curve relates to the stiffness of the structure whereas the peak relates to the strength (Fig. 2). Stress is calculated using force/surface area $\left(\mathrm{N} / \mathrm{mm}^{2}\right)$, strain is calculated using displacement/initial length expressed as a percentage (\%) and stiffness $\left(\mathrm{N} / \mathrm{mm}^{2}\right)$ is the slope of the stress-strain curve, where higher numbers represent decreasing elasticity. When comparing material properties of human tendons and ligaments in the knee, it was found that tendons have a higher stress-strain curve compared to ligaments. In a study of fibrous structures of the human wrist, Kuhlmann et al. found that tendons have a stiffness between 500 and $150 \mathrm{~N} / \mathrm{mm}^{2}$ with a stress to rupture of $35-50 \mathrm{~N} / \mathrm{mm}^{2,13}$. Ligaments on the other hand have stiffness between 40 and $3 \mathrm{~N} / \mathrm{mm}^{2}$ and a stress to rupture of $2-14 \mathrm{~N} / \mathrm{mm}^{2}$. In the same study ligaments are further separated into 3 functional groups. The group of deep intrinsic ligaments of the wrist was found to be the weakest and most elastic of the 3 with a stiffness of $10 \mathrm{~N} / \mathrm{mm}^{2}$, stress to rupture of $3 \mathrm{~N} / \mathrm{mm}^{2}$ and elongation of $40-100 \%$ before rupture ${ }^{13}$. Similar results were also obtained in lower limb studies ${ }^{21}$. Thus, in order to perform their functions in the human body tendons and ligaments have developed different biomechanics, also reflected in 


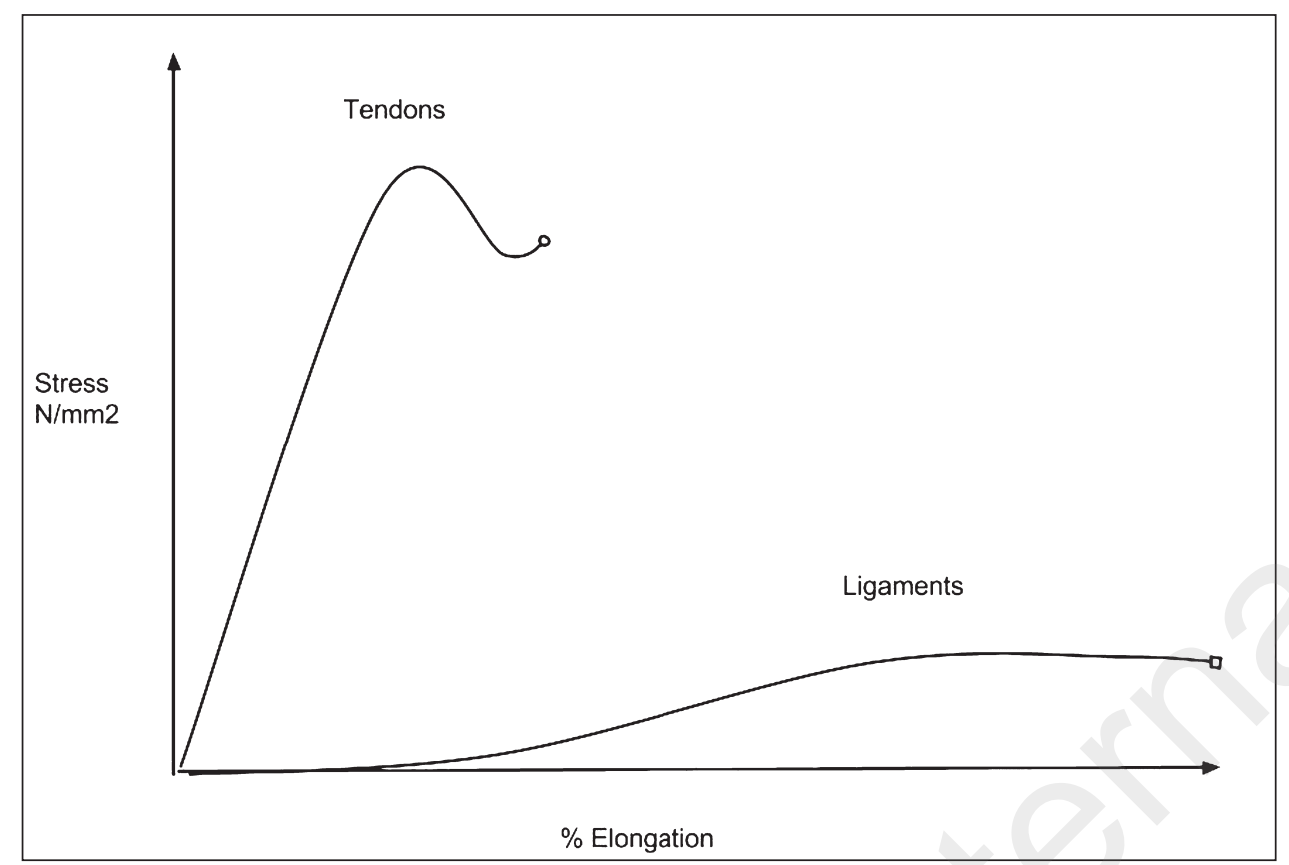

Figure 2. Biomechanics and response to stress between tendons and ligaments.

their biochemical and ultrastructural differences. Tendons are stronger and able to tolerate higher loads with less elongation whereas ligaments are elastic and stretch more under tension.

\section{Ligamentization}

The phenomenon of "ligamentization" was noted first in 1986 with the use of tendon grafts to replace ligaments. It was observed that after ligament reconstruction with tendon grafts, these tendon grafts would take on ligament-like properties. A systematic review of human graft biopsies showed that although tendon grafts undergo this process of ligamentization, significant differences still exist ${ }^{22}$. Tendons that undergo ligamentization lose their larger diameter collagen fibres leading to an ultrastructural composition more similar to that of ligaments although they never achieve the bimodal distribution of the intra-articular ligaments that they are replacing ${ }^{22}$. There is increased cell density, decreased crimp length and increased myofibroblast cell density in the ACL compared to the Achilles tendon (AT) graft at baseline ${ }^{18}$. At 24 weeks after reconstruction with tendon graft, there was a significant increase in graft cell density approaching that of the intact $A C L$, a decrease in crimp length even lower than that of intact $A C L$, and an increase in myofibroblast cell density to over double that of intact $A C L^{18}$. These differences may be due to ligamentization but is also confounded by the fact that there is an increase in myofibroblasts and associated changes in healing tendons and ligaments. Weiler et al. note however, "[the] ligament substitute has not reached the functional status of the intact anterior cruciate ligament, even two years after implantation"18. In a study comparing the healing ACL and $A C L$ grafts in vivo, it was found that early ligament function was dependent on cell population whereas early graft function was dependent on collagen structure. On the longer term, after 12 months, ligament function became more dependent on collagen organization whereas graft function became more dependent on cell number ${ }^{23}$. This may play a role in the differences between ligament healing and ligamentization although the mechanism has not yet been elucidated.

\section{Summary of the above studies}

1. Ligaments are more immature, mefollow-upolically active structures compared to tendons because:

a. Ligaments contain more total DNA

b. Ligaments contain less total collagen

c. Ligaments contain more type III collagen

d. Ligaments have more reducible collagen cross-links

2. Ligaments are more elastic but less resistant to rupture compared to tendons because:

a. Ligaments contain more GAGs and have a higher water content

b. Ligaments have smaller diameter collagen fibres

c. Ligaments have a lower stiffness on the stress-strain curve

d. Ligaments have a lower stress to rupture

e. Ligaments have higher crimp frequency and lower crimp length

f. Ligaments have more SMA containing myofibroblasts, specifically more ovoid and spheroid cell types 
Table III. Comparison of tendon vs ligament properties.

\begin{tabular}{lccccccccccc}
\hline & $\begin{array}{l}\text { DNA } \\
\text { Content }\end{array}$ & $\begin{array}{l}\text { Total } \\
\text { Collagen }\end{array}$ & $\begin{array}{l}\text { Type III } \\
\text { Collagen }\end{array}$ & $\begin{array}{l}\text { Reducible } \\
\text { Collagen } \\
\text { Cross-links }\end{array}$ & $\begin{array}{l}\text { GAG } \\
\text { content }\end{array}$ & Stiffness & $\begin{array}{l}\text { Stress to } \\
\text { Rupture }\end{array}$ & $\begin{array}{l}\text { Crimp } \\
\text { Frequency }\end{array}$ & $\begin{array}{l}\text { Crimp } \\
\text { Length }\end{array}$ & $\begin{array}{l}\text { SMA } \\
\text { myofibro- } \\
\text { blasts }\end{array}$ \\
\hline Tendon & + & +++ & + & + & + & +++ & +++ & + & +++ & + \\
\hline Ligament & +++ & + & +++ & +++ & +++ & + & + & +++ & + & +++ \\
\hline
\end{tabular}

SMA, smooth muscle actin; GAG, glycosaminoglycans.

All of the above findings demonstrate that ligaments are more immature, metabolically active and elastic structures, readily adaptable to environmental changes ${ }^{5,9}$. These differences can be explained by the differing roles of tendons and ligaments in the human body. One hypothesis discussed by Amiel et al. is that tendons may not need to adapt as much to external stresses because they work in continuity with the muscle forming a single contractile unit ${ }^{5}$. Muscles have the ability to stretch, contract and hypertrophy buffering some of the stresses put on the tendon thus resulting in a tendon's decreased need for a metabolically active biochemical structure important in local adaptation, and instead an increased need to be more resistant to the stresses of the contracting muscle. This increased long-term stress may explain why tendons may be more prone to chronic overuse injury compared to ligaments that are more often injured in acute trauma $8,21,24$.

Tendons and ligaments show a clear structure-function relationship resulting in different structural, histological, biochemical and biomechanical properties in order to perform their specific functions within the human body and more specifically within carpal joints (Tab. III). This results in tendons, which are stiffer, stronger and less elastic compared to ligaments. Long-term adverse outcomes after carpal ligament reconstruction include decreased grip strength, decreased range of motion reflected in restricted flexion-extension arcs, as well as graft rupture. Whereas graft strength may be more desirable in lower limb reconstructions due to increased stresses experienced by the knee joints, because of the fine movements performed by the hand, flexibility may be more highly desired especially in those that perform fine manual work. In addition, the carpal joint is a highly complex joint requiring multiple ligament systems to work in collaboration. Due to the differing biomechanics of tendons compared to ligaments, when a tendon is used to replace a ligament, especially in the wrist, the tendon is less able to stretch relative to the ligaments around it and hypothetically is more prone to injury and rupture. As Kuhlmann et al. phrases it, "to replace a ligament by a tendon means to put a string between two pieces of rubber. It will limit the amplitude of the joint and all strains will be concentrated on it. It will yield to rupture very rapidly"13. Very limited comparative clinical studies exist in the literature. This indicates a need for further clinical studies to explore the long-term outcomes of ligament reconstruc- tion with direct comparison between the use of tendon grafts and ligament grafts.

After reviewing the literature, there is a theoretical clinical advantage of using ligaments as a graft source in complex multiaxial joints where stretching and full ROM is crucial (e.g. radiocarpal, carpal joints). Tendons are theoretically more advantageous in mainly uniaxial joints where excessive and constant vector of stress is applied. Future clinical studies must compare range of motion, strength, as well as functional scores and quality of life questionnaires to determine whether there is both an objective and subjective difference in the two graft types.

\section{Conflict of interest statement}

The Authors declare that they have no conflict of interest.

\section{Funding}

None of the Authors has a financial or personal interest in any of the products, devices, or drugs mentioned in this manuscript. This study has no funding entity.

\section{References}

1. Chabas JF, Gay A, Valenti D, Guinard D, Legre R. Results of the modified Brunelli tenodesis for treatment of scapholunate instability: a retrospective study of 19 patients. The Journal of hand surgery. 2008;33(9):1469-1477.

2. Harvey EJ, Berger RA, Osterman AL, Fernandez DL, Weiss AP. Bone-tissue-bone repairs for scapholunate dissociation. The Journal of hand surgery. 2007;32(2):256-264.

3. Luchetti R, Atzei A, Cozzolino R, Fairplay T. Current role of open reconstruction of the scapholunate ligament. Journal of wrist surgery. 2013;2(2):116-125.

4. Spector M. Novel cell-scaffold interactions encountered in tissue engineering: contractile behavior of musculoskeletal connective tissue cells. Tissue engineering. 2002;8(3):351-357.

5. Amiel D, Frank C, Harwood F, Fronek J, Akeson W. Tendons and ligaments: a morphological and biochemical comparison. Journal of orthopaedic research : official publication of the Orthopaedic Research Society. 1984;1(3):257-265.

6. Padulo J, Oliva F, Frizziero A, Maffulli N. Muscles, Ligaments and Tendons Journal - Basic principles and recommendations in clinical and field science research: 2016 update. MLTJ. 2016;6(1):1-5. 
7. Moher D, Liberati A, Tetzlaff J, Altman DG, PRISMA Group Preferred reporting items for systematic reviews and metaanalyses: The PRISMA statement. International Journal of Surgery. 2010;8:336-341.

8. Frank C, Amiel D, Woo SL, Akeson W. Normal ligament properties and ligament healing. Clinical orthopaedics and related research. 1985;196:15-25.

9. Fujii K, Yamagishi T, Nagafuchi T, Tsuji M, Kuboki Y. Biochemical properties of collagen from ligaments and periarticular tendons of the human knee. Knee surgery, sports traumatology, arthroscopy: official journal of the ESSKA. 1994;2(4): 229-233.

10. Johnston RB, Seiler JG, Miller EJ, Drvaric DM. The intrinsic and extrinsic ligaments of the wrist. A correlation of collagen typing and histologic appearance. Journal of hand surgery. 1995;20(6):750-754.

11. Rumian AP, Wallace AL, Birch HL. Tendons and ligaments are anatomically distinct but overlap in molecular and morphological features-a comparative study in an ovine model. Journal of orthopaedic research: official publication of the Orthopaedic Research Society. 2007;25(4):458-464.

12. Benjamin M, Ralphs JR. Tendons and ligaments-an overview. Histology and histopathology. 1997;12(4):1135-1144.

13. Kuhlmann JN, Luboinski J, Laudet C, et al. Properties of the fibrous structures of the wrist. Journal of hand surgery. 1990;15 (3):335-341.

14. Benjamin M, Ralphs JR. The cell and developmental biology of tendons and ligaments. International review of cytology. 2000;196:85-130.

15. Ippolito E, Natali PG, Postacchini F, Accinni L, De Martino C. Ultrastructural and immunochemical evidence of actin in the tendon cells. Clinical orthopaedics and related research. 1977;126:282-284.

16. Murray MM, Spector M. Fibroblast distribution in the anteromedial bundle of the human anterior cruciate ligament: the presence of alpha-smooth muscle actin-positive cells. Journal of orthopaedic research: official publication of the Orthopaedic Research Society. 1999; 17(1):18-27.
17. Spector M. Musculoskeletal connective tissue cells with muscle: expression of muscle actin in and contraction of fibroblasts, chondrocytes, and osteoblasts. Wound repair and regeneration: official publication of the Wound Healing Society [and] the European Tissue Repair Society. 2001;9 (1):11-18.

18. Weiler A, Unterhauser FN, Bail HJ, Huning M, Haas NP. Alpha-smooth muscle actin is expressed by fibroblastic cells of the ovine anterior cruciate ligament and its free tendon graft during remodeling. Journal of orthopaedic research : officia publication of the Orthopaedic Research Society. 2002;20 (2):310-317.

19. Weiss M, Unterhauser FN, Weiler A.Crimp frequency is strongly correlated to myofibroblast density in the human anterior cruciate ligament and its autologous tendon grafts. Knee surgery, sports traumatology, arthroscopy : official journal of the ESSKA. 2012;20(5):889-895.

20. Butler DL, Kay MD, Stouffer DC. Comparison of material properties in fascicle-bone units from human patellar tendon and knee ligaments. Journal of biomechanics. 1986;19(6):425432.

21. Jung HJ, Fisher MB, Woo SL. Role of biomechanics in the understanding of normal, injured, and healing ligaments and tendons. Sports medicine, arthroscopy, rehabilitation, therapy \& technology : SMARTT. 2009;1(1):9.

22. Claes S, Verdonk P, Forsyth R, Bellemans J. The "ligamentization" process in anterior cruciate ligament reconstruction: what happens to the human graft? A systematic review of the literature. The American journal of sports medicine. 2011;39 (11):2473-2476.

23. Proffen BL, Fleming BC, Murray MM. Histologic Predictors of Maximum Failure Loads Differ between the Healing ACL and ACL Grafts after 6 and 12 Months In Vivo. Orthopaedic journal of sports medicine. 2013;1(6).

24. Schechtman $\mathrm{H}$, Bader $\mathrm{DL}$. In vitro fatigue of human tendons. Journal of biomechanics. 1997;30(8):829-835. 